\title{
Ellipsometry and XPS comparative studies of thermal and plasma enhanced atomic layer deposited $\mathrm{Al}_{2} \mathrm{O}_{3}$-films
}

\author{
Jörg Haeberle ${ }^{1}$, Karsten Henkel ${ }^{* 1}$, Hassan Gargouri ${ }^{2}$, Franziska Naumann², \\ Bernd Gruska $^{2}$, Michael Arens ${ }^{2}$, Massimo Tallarida ${ }^{1}$ and Dieter Schmeißer ${ }^{1}$
}

\section{Full Research Paper}

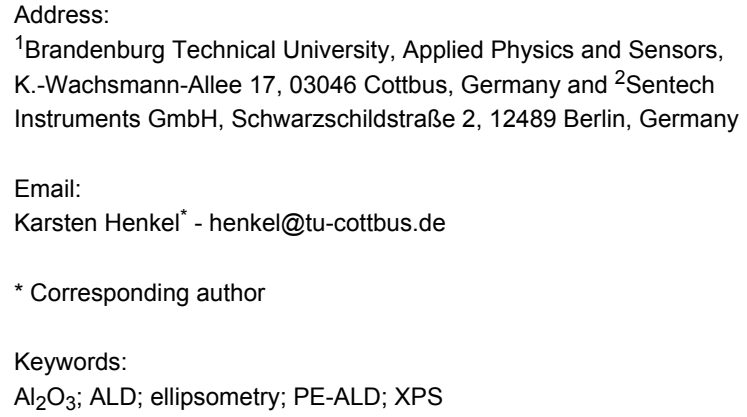

${ }^{1}$ Brandenburg Technical University, Applied Physics and Sensors, K.-Wachsmann-Allee 17, 03046 Cottbus, Germany and ${ }^{2}$ Sentech Instruments $\mathrm{GmbH}$, Schwarzschildstraße 2, 12489 Berlin, Germany

Email:

Karsten Henkel* - henkel@tu-cottbus.de

* Corresponding author

Keywords:

$\mathrm{Al}_{2} \mathrm{O}_{3} ; \mathrm{ALD}$; ellipsometry; PE-ALD; XPS

\author{
Beilstein J. Nanotechnol. 2013, 4, 732-742. \\ doi:10.3762/bjnano.4.83 \\ Received: 30 June 2013 \\ Accepted: 23 October 2013 \\ Published: 08 November 2013 \\ This article is part of the Thematic Series "Energy conversion applications \\ of atomic layer deposition". \\ Guest Editor: J. Bachmann
}

(C) 2013 Haeberle et al; licensee Beilstein-Institut.

License and terms: see end of document.

\begin{abstract}
We report on results on the preparation of thin $(<100 \mathrm{~nm})$ aluminum oxide $\left(\mathrm{Al}_{2} \mathrm{O}_{3}\right)$ films on silicon substrates using thermal atomic layer deposition (T-ALD) and plasma enhanced atomic layer deposition (PE-ALD) in the SENTECH SI ALD LL system. The T-ALD $\mathrm{Al}_{2} \mathrm{O}_{3}$ layers were deposited at $200{ }^{\circ} \mathrm{C}$, for the PE-ALD films we varied the substrate temperature range between room temperature (rt) and $200{ }^{\circ} \mathrm{C}$. We show data from spectroscopic ellipsometry (thickness, refractive index, growth rate) over 4 " wafers and correlate them to X-ray photoelectron spectroscopy (XPS) results. The $200{ }^{\circ} \mathrm{C}$ T-ALD and PE-ALD processes yield films with similar refractive indices and with oxygen to aluminum elemental ratios very close to the stoichiometric value of 1.5 . However, in both also fragments of the precursor are integrated into the film. The PE-ALD films show an increased growth rate and lower carbon contaminations. Reducing the deposition temperature down to rt leads to a higher content of carbon and $\mathrm{CH}$-species. We also find a decrease of the refractive index and of the oxygen to aluminum elemental ratio as well as an increase of the growth rate whereas the homogeneity of the film growth is not influenced significantly. Initial state energy shifts in all PE-ALD samples are observed which we attribute to a net negative charge within the films.
\end{abstract}

\section{Introduction}

Thin aluminum oxide $\left(\mathrm{Al}_{2} \mathrm{O}_{3}\right)$ layers deposited by atomic layer deposition (ALD) have been investigated for several applications like surface passivation or encapsulation in organic and inorganic photovoltaic devices [1,2], interfacial buffering for high-k dielectrics [3,4], organic memories [5], and nano-laminates [6] as well as work function modification [7], gas diffusion barrier [8] or corrosion protection [9]. Recently, there is a growing activity in covering photo-electrodes or electrodes by 
ultra-thin $\mathrm{Al}_{2} \mathrm{O}_{3}$ ALD layers for electrochemical energy generation and storage systems [10] in order to enhance the efficiency and durability of such devices. This includes for example solar energy conversion systems like dye sensitized solar cells $[11,12]$ and water splitting devices [13] or lithium ion batteries [14]. Here, in particular the excellent conformability of ALD growth over high surface area materials and its uniformity and self-termination [15] were beneficially applied. Furthermore, $\mathrm{Al}_{2} \mathrm{O}_{3} \mathrm{ALD}$ layers have shown their ability as gate dielectrics for future graphene based electronics [16].

The most commonly used ALD sequence for thermal ALD (T-ALD) is the pulsed alternation of trimethyl-aluminum (TMA) as metal source and water as oxygen source, respectively $[1,15,17]$. Within the last decade the research have been extended to plasma enhanced ALD (PE-ALD) in which the $\mathrm{H}_{2} \mathrm{O}$ as oxygen source is replaced by a plasma exposure $\left(\mathrm{O}_{2}\right.$, $\mathrm{O}_{3}$ ) $[1,17,18]$. Caused by the higher reactivity of the plasma generated oxygen radicals the PE-ALD extends the capabilities of ALD such as improved film quality, increased flexibility in process conditions [17,18], and is in particular preferred over thermal ALD for lower substrate temperatures due to lower impurity levels $[1,18]$. The latter allows further the ALD use in organic and in particular flexible electronic applications or on thermally fragile substrates $[2,8,15,18]$.

Recently the Kessels group has reviewed the state of the art of plasma-assisted ALD [18] and surface passivation schemes of $\mathrm{Al}_{2} \mathrm{O}_{3}$ prepared by ALD [1]. This group has reported also on the modeling of reaction regimes influencing the conformality of the PE-ALD process [19]. Herein the typical parameters like growth rate per cycle (GPC), density and refractive index were determined by ellipsometry whereas the elemental composition was mostly deduced from Rutherford Backscattering Spectrometry (RBS). The influence of the substrate temperature onto these parameters was discussed, also when a commercial $200 \mathrm{~mm}$ ALD reactor was used [20]. However characterizations based X-ray photoelectron spectroscopy (XPS) in dependence of the substrate temperature are not shown in that reviews. Furthermore to our knowledge there seems to be a lack in reports about dielectric parameters in dependence of the substrate temperature for PE-ALD as mostly comparisons are given at fixed temperatures $[1,21]$ or only for T-ALD samples [22].

In this paper we show a comparison of $\mathrm{Al}_{2} \mathrm{O}_{3}$ samples prepared by T-ALD and PE-ALD respectively based on ellipsometry and on X-ray photoelectron spectroscopy measurements (XPS). The substrate temperature in the PE-ALD process was varied from $200{ }^{\circ} \mathrm{C}$ downwards to room temperature (rt). The Sentech ALD reactor system is applicable for both processes (see Experimental section). In that way we are able to investigate samples which are produced in the same chamber avoiding the influence which might be caused by variations of different ALD systems. In the first part we evaluate the newly developed SENTECH's SI ALD LL system by comparison of homogeneity, GPC, and refractive index with recently reported values in the literature whereas in the second part the oxygen to aluminum $(\mathrm{O} / \mathrm{Al})$ ratio and carbon contaminations are discussed. Dielectric parameters of these films will be discussed elsewhere [23].

\section{Results and Discussion \\ Thickness and homogeneity (ellipsometry)}

First, we report on the thickness homogeneity of the T-ALD and PE-ALD layers. Film thickness and refractive index of the deposited layers were determined using a SENTECH SE 800 spectroscopic ellipsometry instrument (for details see experimental section). Figure 1 depicts the thickness distributions of the PE-ALD layers prepared at $200{ }^{\circ} \mathrm{C}, 80^{\circ} \mathrm{C}$ and rt; for comparison a film produced at typical T-ALD conditions at $200{ }^{\circ} \mathrm{C}$ is shown.

Figure 2a summarizes these homogeneity results in dependence of the substrate temperature. Both, the T-ALD and PE-ALD layers prepared at $200{ }^{\circ} \mathrm{C}$ show very good homogeneities with non-uniformities of only $\pm 0.5 \%$ and $\pm 0.8 \%$, respectively. For the PE-ALD layers produced at $80{ }^{\circ} \mathrm{C}( \pm 1.1 \%)$ and $\mathrm{rt}( \pm 1.2 \%)$ the values are only slightly increased. For thinner PE-ALD layers $(\approx 10 \mathrm{~nm}$, also shown in Figure 2 a) the homogeneity remains approximately the same for $T>100{ }^{\circ} \mathrm{C}$. Below this temperature the inhomogeneity increases to $\pm 2.5 \%$ and $\pm 3.8 \%$ at $80{ }^{\circ} \mathrm{C}$ and $\mathrm{rt}$, respectively. Assuming the same roughness in the thicker and thinner layers at the same process temperature, the influence of the roughness on the thickness distribution is increased for the thinner layer. Therefore we argue that at lower temperatures the roughness is increased compared to the layers at $T>100^{\circ} \mathrm{C}$.

Parasitic chemical vapour deposition (CVD) like reactions due to remaining TMA precursor within the reactor caused by not optimal purge times as well as a radial non-uniformity of the plasma species are believed to be responsible for the thickness non-uniformity in the PE-ALD process [1].

\section{Growth rate and refractive index (ellipsometry)}

The growth rate per cycle and the refractive index at $632.8 \mathrm{~nm}$ wavelength are deduced from the ellipsometry data and plotted versus growth temperatures in Figure $2 \mathrm{~b}$ and $2 \mathrm{c}$. For the PE-ALD process the growth rate of the $\mathrm{Al}_{2} \mathrm{O}_{3}$ film increases from $1.2 \AA$ /cycle to $2 \AA$ /cycle, whereas the refractive index decreases from 1.64 to 1.56 when the substrate temperature is 

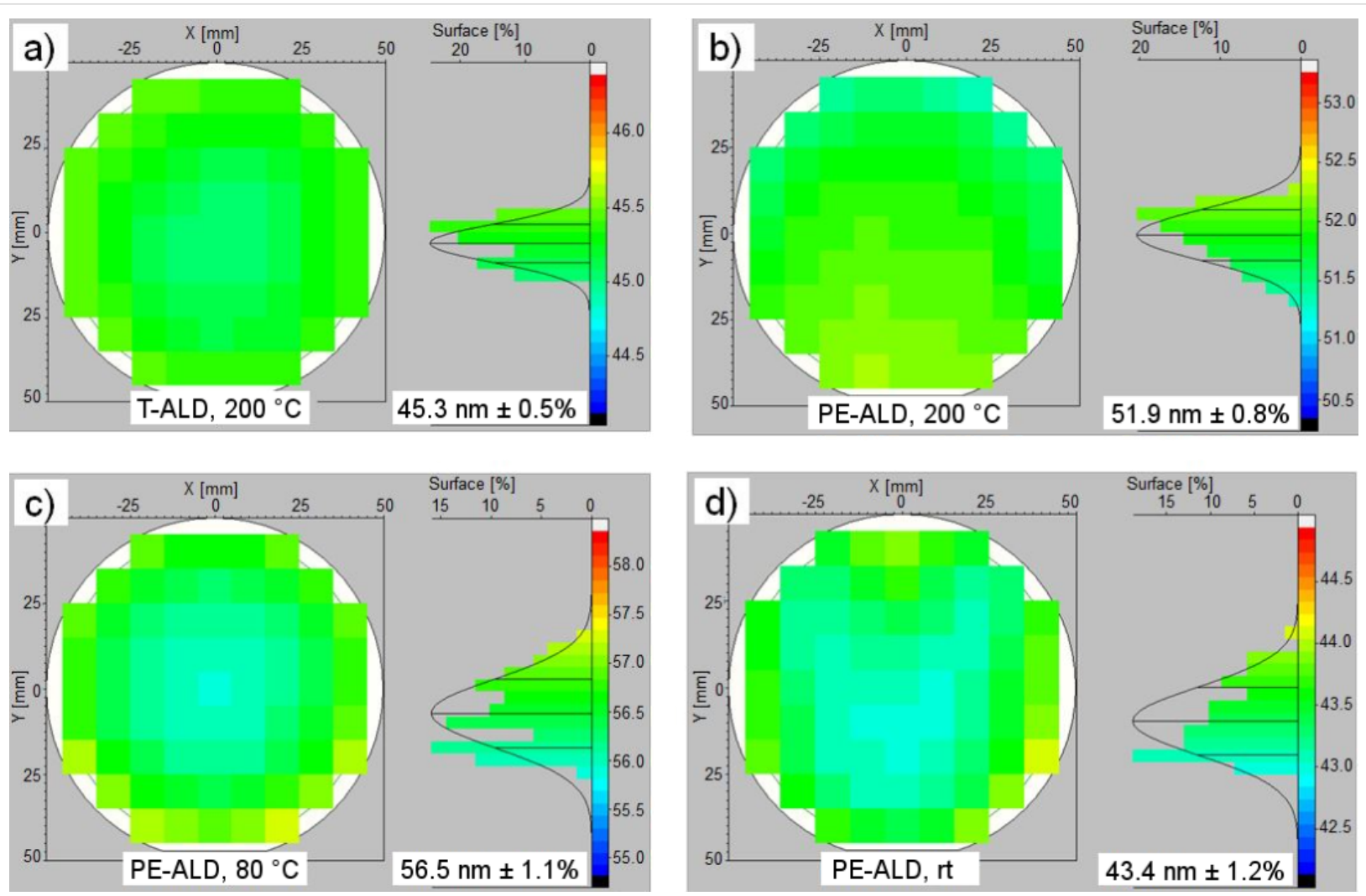

Figure 1: Thickness distributions of T-ALD at $200^{\circ} \mathrm{C}$ (a) and PE-ALD films at $200^{\circ} \mathrm{C}$ (b), $80^{\circ} \mathrm{C}$ (c) and $\mathrm{rt}$ (d). The data were recorded by ellipsometry. The left part of every fraction shows the thickness distribution over 4 inch wafers $(\varnothing=100 \mathrm{~mm}$ ) and the right part its statistics. The thickness average and the uniformity of the layer over the 4 inch wafer are given within the graphs.

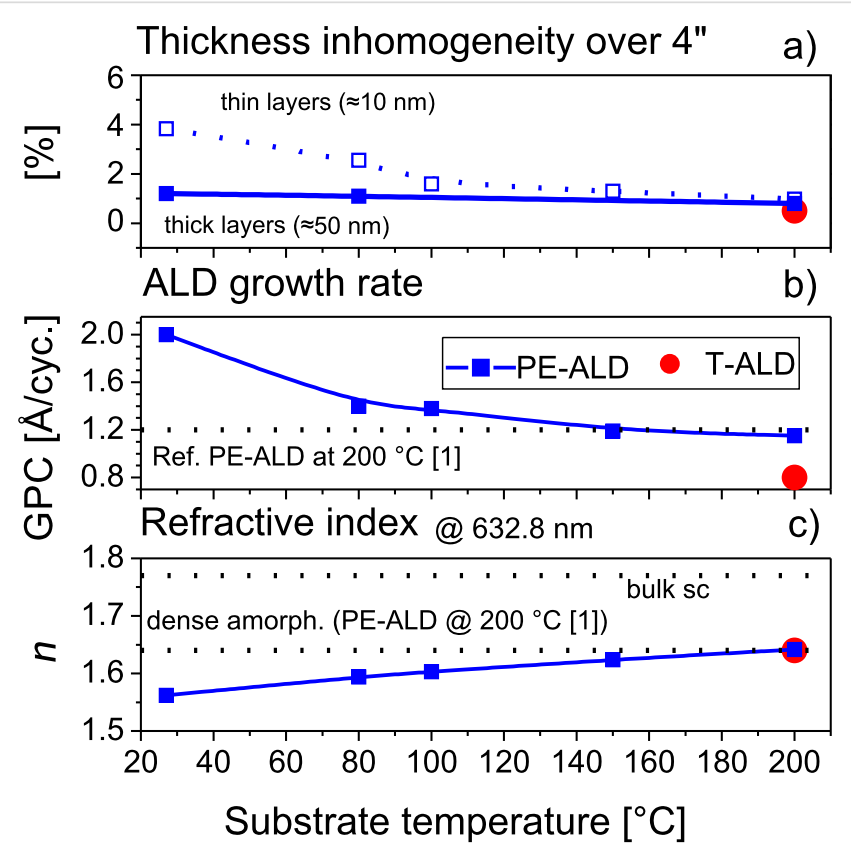

Figure 2: Ellipsometry results showing thickness homogeneity (a), growth rate (b) and refractive index at $632.8 \mathrm{~nm}(\mathrm{c})$ in dependence of the substrate temperature of PE-ALD layers (blue squares, filled: $\approx 50 \mathrm{~nm}$ thick films, open: $\approx 10 \mathrm{~nm}$ thick films). The data of the T-ALD film at $200{ }^{\circ} \mathrm{C}$ are included (red filled circle). For orientation the reference values of the growth rate and refractive index reported for dense amorphous layers (PE-ALD, $200^{\circ} \mathrm{C}$ ) in literature [1] and the bulk single crystalline (sc) value of the refractive index are illustrated by dashed lines. 
reduced from $200{ }^{\circ} \mathrm{C}$ down to rt. The data of the PE-ALD at $200{ }^{\circ} \mathrm{C}$ and also the temperature dependency of the growth rate are in very good agreement with values reported by the Kessels group [1]. Also the trend of the refractive index is very similar to reported values by the George group $[8,15]$ for the thermal ALD in the temperature range between $33^{\circ} \mathrm{C}$ and $177^{\circ} \mathrm{C}$. For comparison, our thermal ALD procedure for $\mathrm{Al}_{2} \mathrm{O}_{3}\left(200{ }^{\circ} \mathrm{C}\right)$ delivers a growth rate of $0.8 \AA$ /cycle and a refractive index of 1.64, these value are also included in Figure 2.

The observed reduction of the refractive index at lower temperatures corresponds to a slightly reduced mass density $[8,15,18]$. This might be also partly responsible for the increased GPC values. However, the main driving force for the higher GPC at lower temperatures is attributed to an increased incorporation of aluminum atoms into the layers due to a higher surface density of hydroxyl groups as the dominant adsorption sites for TMA [18]. At higher temperatures thermally activated dehydroxylation reactions occur and the GPC decreases [1]. In addition the CVD parasitic reactions mentioned above may lead to the dissociation of the TMA precursor resulting in higher GPC values [1].

\section{Oxygen to aluminum elemental ratios (XPS)}

The chemical composition of the $\mathrm{Al}_{2} \mathrm{O}_{3}$ films prepared at different temperatures was investigated by XPS. Based on the general trends reported above, here the PE-ALD layers at $200{ }^{\circ} \mathrm{C}, 80^{\circ} \mathrm{C}$ and $\mathrm{rt}$ as well as the T-ALD sample $\left(200^{\circ} \mathrm{C}\right)$ were measured. The XPS survey spectra (Figure 3 ) of PE-ALD samples $\left(200^{\circ} \mathrm{C}, 80^{\circ} \mathrm{C}\right.$, rt $)$ and of the T-ALD $\left(200^{\circ} \mathrm{C}\right)$ sample depict mainly $\mathrm{Al}$ and $\mathrm{O}$ contributions but also carbon contamination. The latter will be discussed below.

Now we focus on the details of the XPS analysis, in particular on the values of the observed peak positions, the carbon

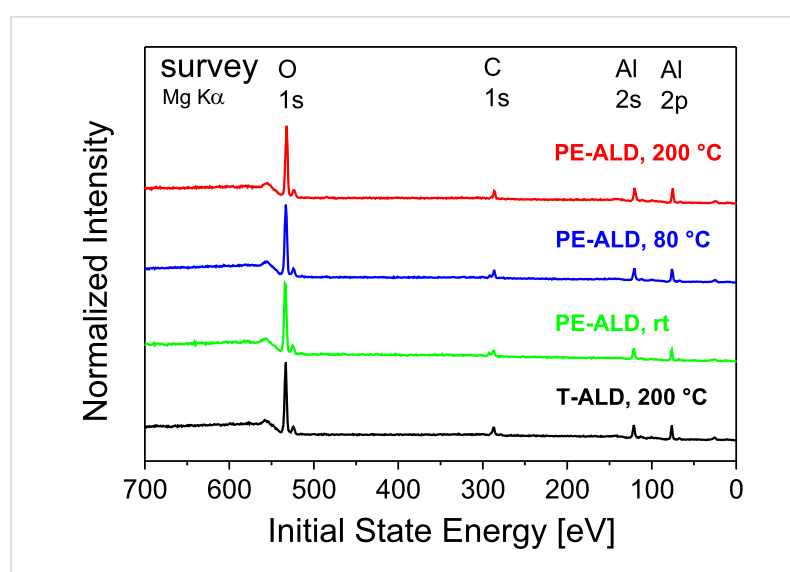

Figure 3: XPS survey spectra (Mg Ka) of the PE-ALD layers deposited at $200{ }^{\circ} \mathrm{C}$ (red curve), $80^{\circ} \mathrm{C}$ (blue) and rt (green) and the T-ALD at $200^{\circ} \mathrm{C}$ (black). The main core levels are labeled. For better comparison the data are normalized to each 01 s peak maximum and separated vertically, but shown in the same scaling.

content, the contributions in the peak profiles of the A12p and O1s core levels. We also discuss the origin of the observed peak shifts.

\section{Peak positions}

In Figure $4 \mathrm{a}$ and $4 \mathrm{~b}$ we show the detailed spectra of the O1s and A12p core levels. First we notice that all observed peak positions appear at very high initial state (IS) energy values. Second, the observed values depend significantly on the preparation conditions and vary within 1 to $1.5 \mathrm{eV}$. The peak maxima of the O1s and A12p core levels of the T-ALD sample appear at $533.2 \mathrm{eV}$ and $76.3 \mathrm{eV}$ IS energy. It is obvious that the positions of the peak maxima are shifted towards lower IS energy in both, the O1s and the A12p data for the PE-ALD samples, except for the O1s of the rt sample discussed below. The observed energy values for the individual core levels and the corresponding FWHM are listed also in Table 1 for the individual samples.
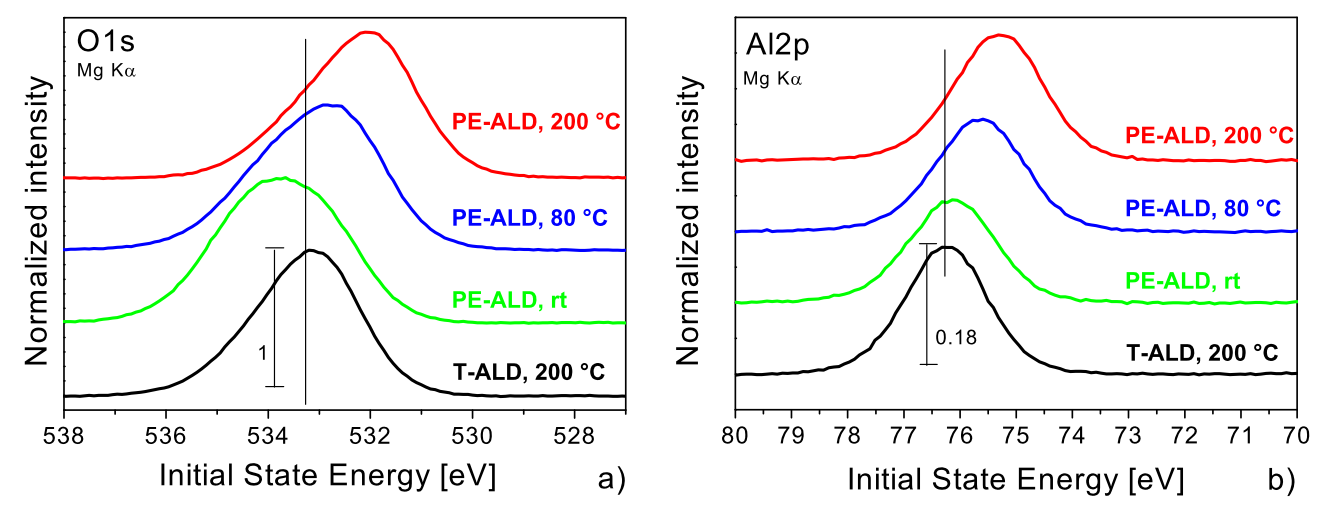

Figure 4: $\mathrm{O} 1 \mathrm{~s}(\mathrm{a})$ and $\mathrm{Al} 2 \mathrm{p}$ (b) core level spectra (Mg Ka) of the PE-ALD layers deposited at $200{ }^{\circ} \mathrm{C}$ (red curve), $80{ }^{\circ} \mathrm{C}(\mathrm{blue})$ and rt (green) and the T-ALD at $200^{\circ} \mathrm{C}$ (black). The data are normalized to each O1s peak maximum and separated vertically, but shown in the same scaling. The IS energy is referred to the Fermi energy. 
Table 1: Summary of the data determined in this contribution for PE-ALD layers at $\left(200{ }^{\circ} \mathrm{C}, 80^{\circ} \mathrm{C}\right.$, rt $)$ and the T-ALD film at $200{ }^{\circ} \mathrm{C}$. The XPS data shown here are based on Mg Ka excitation.

\begin{tabular}{|c|c|c|c|c|c|}
\hline \multicolumn{2}{|l|}{ ALD - Process } & \multirow{2}{*}{$\begin{array}{c}T \\
200\end{array}$} & \multirow{2}{*}{$\begin{array}{c}P E \\
27(r t)\end{array}$} & \multirow{2}{*}{$\begin{array}{l}P E \\
80\end{array}$} & \multirow{2}{*}{$\begin{array}{c}P E \\
200\end{array}$} \\
\hline Temperature $\left[{ }^{\circ} \mathrm{C}\right]$ & & & & & \\
\hline \multirow[t]{2}{*}{ Thickness Inhomogeneity [\%] } & $\approx 50 \mathrm{~nm}$ & 0.5 & 1.2 & 1.1 & 0.8 \\
\hline & $\approx 10 \mathrm{~nm}$ & n.d. & 3.8 & 2.5 & 0.98 \\
\hline Growth rate $[\AA /$ cycle $]$ & & 0.8 & 2.0 & 1.4 & 1.2 \\
\hline Refractive index & & 1.64 & 1.56 & 1.59 & 1.64 \\
\hline O/AI ratio (XPS) & & 1.46 & 1.20 & 1.32 & 1.47 \\
\hline C/AI (EDX) & & n.d. & 0.22 & 0.16 & 0.07 \\
\hline $\mathrm{C}(\mathrm{XPS})[\%]$ & & 11 & 14 & 14 & 8 \\
\hline $\mathrm{Al} 2 \mathrm{p}$ peak position/FWHM [eV] & & $76.3 / 1.7$ & $76.1 / 1.8$ & $75.6 / 1.9$ & $75.3 / 1.9$ \\
\hline O1s peak position/FWHM [eV] & & $533.2 / 2.4$ & $533.7 / 3.0$ & $532.8 / 2.9$ & $532.1 / 2.6$ \\
\hline C1s peak position/FWHM [eV] & & $286.9 / 1.8$ & 287.1/1.9 & $286.5 / 1.9$ & $286.2 / 2.0$ \\
\hline
\end{tabular}

\section{Carbon contributions}

It should be noted that the generally used approach to refer the IS energy to the position of the $\mathrm{C} 1 \mathrm{~s}$ contribution cannot be applied here. One reason is that the carbon species are not associated with adsorbed methyl groups $(284.5 \mathrm{eV})$ or adsorbed hydro-carbons $(285 \mathrm{eV})$ but are inserted in an oxidic matrix. The formation of $\mathrm{C}-\mathrm{O}$ bonds results in core level energies at around $286 \mathrm{eV}$ (Figure 5). Second, the peak position of the $\mathrm{C} 1 \mathrm{~s}$ (Figure 5) varies in the same way as that of the Al2p and the O1s core levels. This indicates that all peak positions are shifted due to the individual preparation conditions.

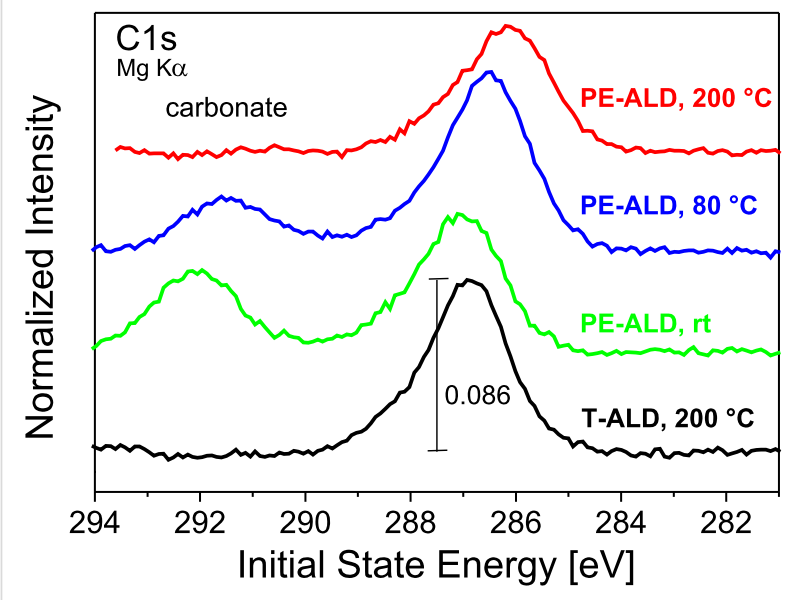

Figure 5: $\mathrm{C} 1 \mathrm{~s}$ core level spectra $(\mathrm{Mg} \mathrm{Ka})$ of the PE-ALD layers deposited at $200{ }^{\circ} \mathrm{C}$ (red curve), $80^{\circ} \mathrm{C}$ (blue) and rt (green) and the T-ALD at $200{ }^{\circ} \mathrm{C}$ (black). The data are normalized to each O1s peak maximum and separated vertically, but shown in the same scaling. The energy is referred to the Fermi energy.

In case that the peak positions would be referred to $\mathrm{C} 1 \mathrm{~s}$ positions at a fixed energy (e.g., $285 \mathrm{eV}$ ) we would still observe a shift in the IS energies of both the O1s and A12p core levels.
This is exemplarily illustrated in Figure 6 for the A12p. All PE-ALD samples exhibit a similar remaining shift of about $400 \mathrm{meV}$. This we attribute to fixed oxide charges (see below).

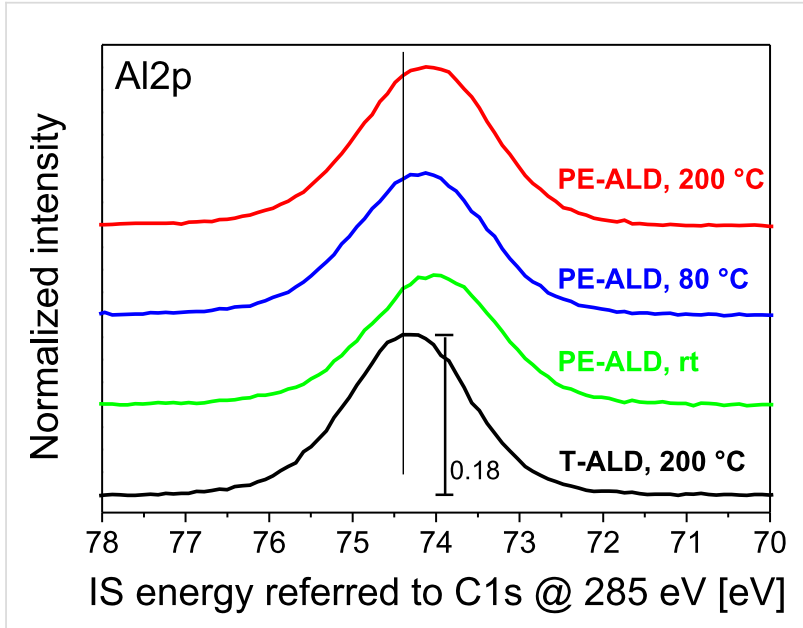

Figure 6: Al2p core level spectra (Mg Ka) of the PE-ALD layers deposited at $200^{\circ} \mathrm{C}$ (red curve), $80^{\circ} \mathrm{C}$ (blue) and rt (green) and the T-ALD at $200^{\circ} \mathrm{C}$ (black) when referred to a fixed C1s peak position of $285 \mathrm{eV}$ for every sample. The data are normalized to each O1s peak maximum and separated vertically, but shown in the same scaling.

Also, due to the fact that we observe significant $\mathrm{C} 1 \mathrm{~s}$ intensities - we have to consider the contributions from carbonate species [24]. These are incorporated by the precursor side groups which do not desorb completely during the purging periods. The combustion like character of the PE-ALD process yields also COO side products $[1,18]$.

\section{Peak profiles}

The profiles and FWHM of the core levels can be analyzed to give information about the chemical neighborhood of the individual elements. The data in Figure 4 indicate that both, the 
$\mathrm{A} 12 \mathrm{p}$ and the O1s levels are rather broad and have some asymmetric profile. Only for the T-ALD sample the shape of the $\mathrm{A} 12 \mathrm{p}$ is rather symmetric and can be decomposed by one single peak which we assign to $\mathrm{Al}-\mathrm{O}[1,24,25]$. In contrast, the O1s signal exhibits a shoulder towards higher IS energies. For the PE-ALD samples the line width is broader, in general, and the asymmetries are more pronounced.

We attribute the broadening to the existence of hydroxyl $(\mathrm{OH})$ groups [24] which are incorporated within the films by the usage of the $\mathrm{H}_{2} \mathrm{O}$ oxidant in T-ALD or the higher oxidation potential of the PE-ALD process causing other $\mathrm{H}_{2} \mathrm{O}$ side products $[1,18]$.

In Figure 7 we have analyzed the profiles of the $\mathrm{O} 1 \mathrm{~s}$ signals of the PE-ALD samples at $\mathrm{rt}$ (Figure 7a) and at $80^{\circ} \mathrm{C}$ (Figure 7b) in more detail. In order to allow a comparison to literature values the spectra are referred in this case to fixed $\mathrm{C} 1 \mathrm{~s}$ core levels. Here the main signal arising from the $\mathrm{Al}-\mathrm{O}$ bonds $[24,25]$ is found at $531.2 \mathrm{eV}$ for both samples. The second contribution caused by the additional hydroxyl and carbonate species [24] appear at $532.6 \mathrm{eV}$ and $532.7 \mathrm{eV}$, respectively.

Our assignment of the peak positions is for thick $\mathrm{Al}_{2} \mathrm{O}_{3}$ films where the screening of the photo-excited hole is by the electrostatic potentials of the oxide neighbors while screening from the substrate is negligible [26]. It should be mentioned that these values may differ from those of ultra-thin Al-oxide films reported elsewhere [1,24]. We should emphasize again that the individual IS energy positions for the main Al-O signal depends on the preparation condition of the individual films as these influence the dielectric screening significantly [3,6,27].
From the combination of these data with the $\mathrm{C} 1 \mathrm{~s}$ core level data (Figure 5) it becomes evident that the rt PE-ALD sample has the highest carbonate content leading to distinct contribution at higher IS energy within the O1s core level data. They compete with the above mentioned and below discussed peak shifting to lower IS energy. Therefore the O1s peak maximum of the rt PE-ALD sample is shifted to higher IS energy with respect to the T-ALD $200{ }^{\circ} \mathrm{C}$ sample whereas the peak maximum is moved to lower IS energy in the A12p core level, where the carbonate has no influence. The same fact is due for the $80{ }^{\circ} \mathrm{C}$ PE-ALD sample where the O1s peak maxima is almost at the same position like in the T-ALD $200{ }^{\circ} \mathrm{C}$ sample but the A12p exhibits a shift into the same direction like in the other PE-ALD samples.

\section{Relative O/Al ratios}

Based on this data analysis the elemental ratio of oxygen to aluminum was determined. We used the peak areas of the Al-O contributions within the $\mathrm{O} 1 \mathrm{~s}$ and $\mathrm{A} 12 \mathrm{p}$ core levels (i.e., the contributions assigned to $\mathrm{COO}$ and $\mathrm{OH}$ groups were not considered). We used the element specific cross sections of 0.063467 and of 0.012295 for $\mathrm{O} 1 \mathrm{~s}$ and $\mathrm{A} 12 \mathrm{p}$, respectively [28]. The resulting $\mathrm{O} 1 \mathrm{~s}_{\mathrm{Al}-\mathrm{O}} / \mathrm{A} 12 \mathrm{p}_{\mathrm{Al}-\mathrm{O}}$ ratios are plotted versus the substrate temperature in Figure 8. For the samples prepared at $200{ }^{\circ} \mathrm{C}$ substrate temperature we find ratios of 1.46 and 1.47 for both, the T-ALD and the PE-ALD samples. These values are close to the stoichiometric value of 1.5. When the temperature in the PE-ALD process is lowered we observe a significant reduction of the $\mathrm{O} / \mathrm{Al}$ ratio as shown in Figure 8 . It points out that at these lower temperatures $\left(80^{\circ} \mathrm{C}, \mathrm{rt}\right)$ the oxygen radicals are less efficient in oxidizing the aluminum precursor. This is true also for the chemisorbed organic precursor molecules.
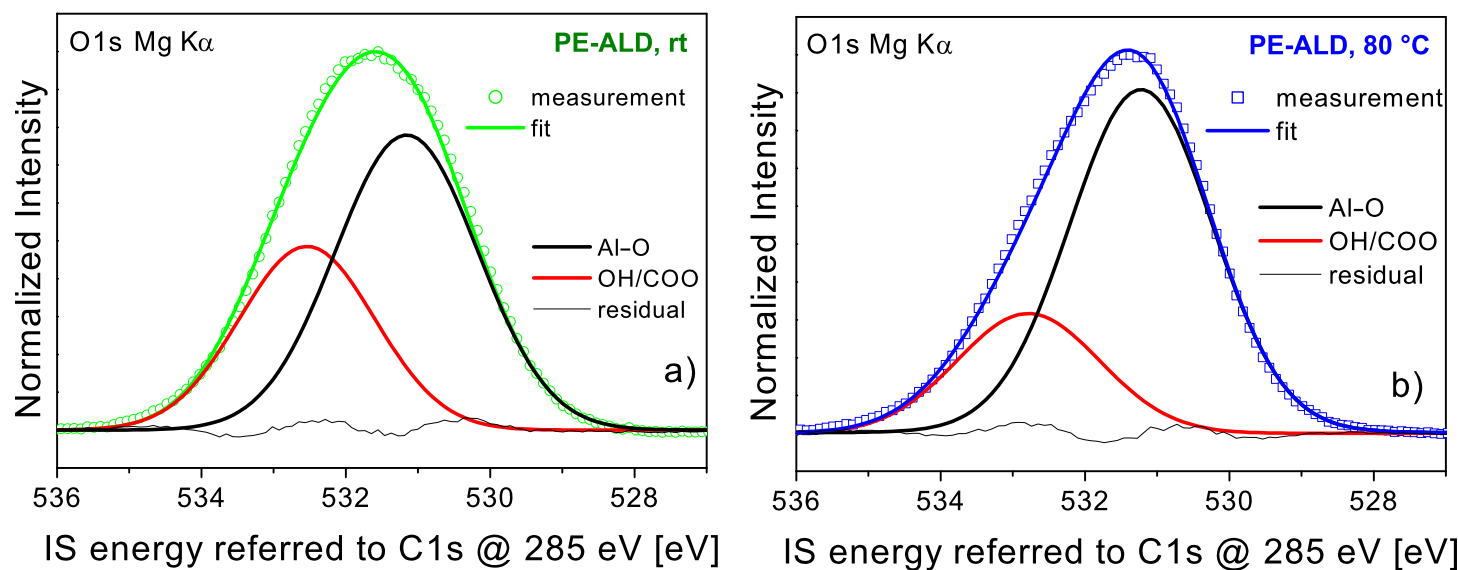

Figure 7: $\mathrm{O} 1 \mathrm{~s}$ core level spectra $(\mathrm{Mg} \mathrm{Ka})$ of the PE-ALD samples prepared at $\mathrm{rt}(\mathrm{a})$ and $80{ }^{\circ} \mathrm{C}(\mathrm{b})$ substrate temperature. The peak decomposition into Al-O (black curves) and $\mathrm{OH} / \mathrm{COO}$ components (red) are indicated. The measured data are given by green hollow circles (rt) and blue hollow squares $\left(80^{\circ} \mathrm{C}\right)$ whereas the resulting fitting curve is shown in corresponding line colors (residual: thin black line). The data are normalized to the measured $01 \mathrm{~s}$ peak maximum of each sample and both diagrams are shown in an identical scale. The IS energy is referred to fixed $\mathrm{C} 1 \mathrm{~s}$ levels for every sample at $285 \mathrm{eV}$. 


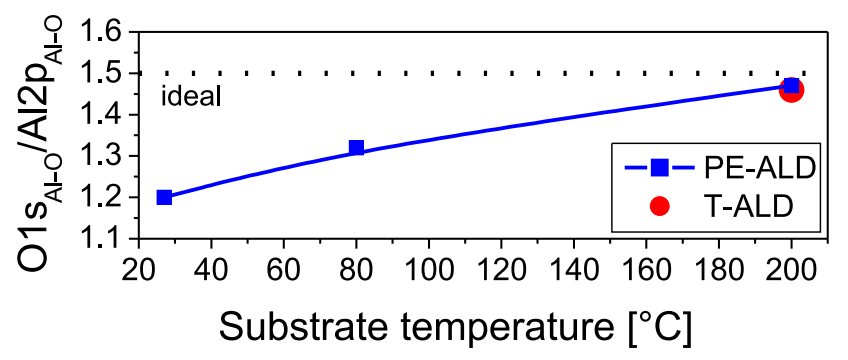

Figure 8: $\mathrm{O} 1 \mathrm{~s}$ to $\mathrm{Al} 2 \mathrm{p}$ elemental ratio versus substrate temperature of PE-ALD layers (blue squares); the data point of the T-ALD film at $200{ }^{\circ} \mathrm{C}$ is included (red filled circle). Here, only the Al-O contributions were considered for the analysis. For orientation the ideal stoichiometric value is illustrated by the dashed line.

At first sight our results might contradict the composition results of the Kessels group based on RBS data where oxygen rich layers were found at lower temperatures $[1,20]$. However, we have analyzed here only the Al-O specific contributions. In case that also $\mathrm{OH}$ and $\mathrm{COO}$ contributions would be considered for the analysis $\mathrm{O} / \mathrm{Al}$ ratios of 1.9 and 1.8 would be deduced for the PE-ALD samples at $\mathrm{rt}$ and $80{ }^{\circ} \mathrm{C}$ substrate temperature, respectively, very similar to the results in [20].

\section{Influence of fixed charges}

Regarding the shifts of the IS energy of the O1s and distinctly in the A12p core levels of the PE-ALD samples we argue that they might be caused by a net negative fixed charge which is built-up in particular in PE-ALD samples as reported in literature $[1,18,22,29]$. Our capacitance-voltage measurements on these layers (to be reported elsewhere, [23]) indeed yield a negative fixed charge which is in the range of 0.5 to $5 \times 10^{12} \mathrm{~cm}^{-2}$ for the PE-ALD samples. For the $200{ }^{\circ} \mathrm{C}$ T-ALD sample it is only about $2 \times 10^{11} \mathrm{~cm}^{-2}$.
Tetrahedral coordinated Al has a charge of -3 [29] and can be counted as an aluminum vacancy which can react with an oxygen atom originating from the $\mathrm{SiO}_{2}$ interface resulting in a net negative charge [1,29]. Moreover, oxygen interstitials may be responsible for the net negative fixed charge [1]. However, the microscopic origin of this charge is still under discussion [1]. Therefore, we plan to conduct X-ray absorption as well as resonant photoemission measurements using synchrotron radiation (SR) in near future.

Now we report on a direct comparison of the $200{ }^{\circ} \mathrm{C}$ PE-ALD and T-ALD samples. The results are depicted in Figure 9. First, we focused on the line positions of the O1s (Figure 9a) and A12p (Figure 9b) core levels using SR and observed the same or only slightly shifted IS energies compared to the lab experiments with $\mathrm{Mg} \mathrm{K} \alpha$ excitation (compare to Figure 4a and Figure $4 \mathrm{~b}$ ). The IS energy shifts between the PE-ALD and T-ALD samples in the synchrotron experiment are a bit smaller compared to the $\mathrm{Mg} \mathrm{K} \alpha$ lab measurement. This might be due to
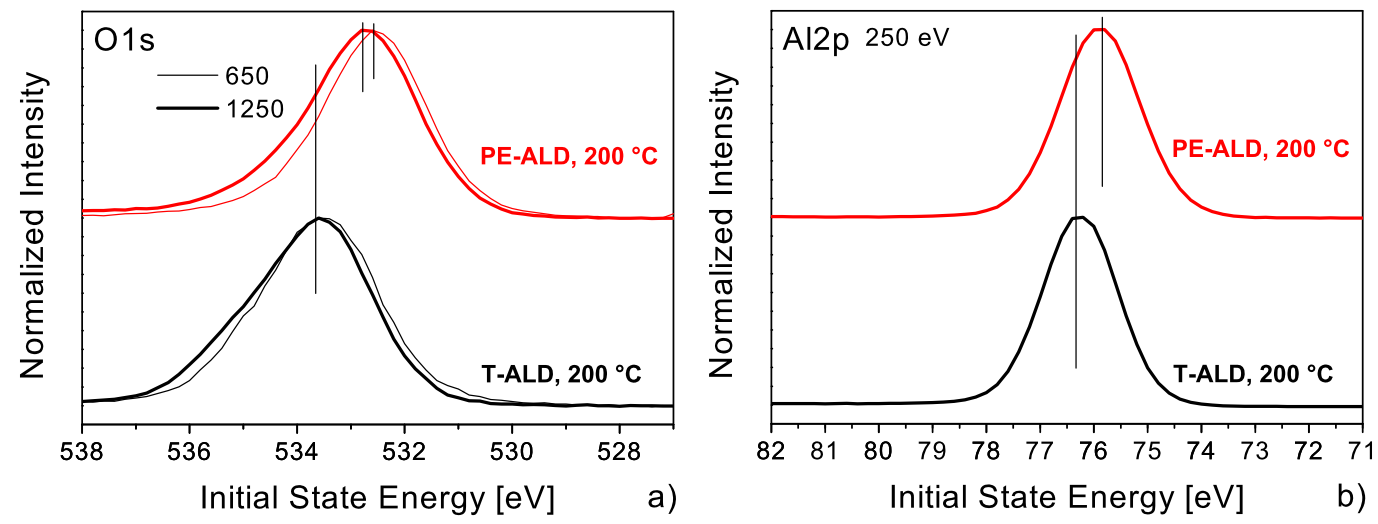

Figure 9: O1s (a) and AI2p (b) core level spectra of the PE-ALD (red curves) and T-ALD layers (black) deposited at $200{ }^{\circ} \mathrm{C}$. These data were recorded with synchrotron excitation. The excitation energies were $650 \mathrm{eV}$ (thick lines) and $1250 \mathrm{eV}$ (thin lines) for the O1s and $250 \mathrm{eV}$ for the Al2p, respectively. The data are normalized to each individual peak maximum and separated vertically, but shown in the same scaling. The IS energy is referred to Fermi energy. 
the higher light intensity at the synchrotron which might lead to a filling/defilling of fixed charges. To check further whether the mentioned shifts of the core levels of the PE-ALD samples in comparison to the T-ALD sample originate from some surface bend bending we measured the $\mathrm{O} 1 \mathrm{~s}$ core level at different excitation energies (Figure 9a). In the T-ALD sample we observe no difference in the line position between the more surface $(650 \mathrm{eV})$ and more bulk sensitive $(1250 \mathrm{eV})$ mode, whereas in the PE-ALD a small shift of $150 \mathrm{meV}$ is within experimental error bars. Therefore we conclude that the shifts in the core levels of the PE-ALD samples are real and not caused by effects like surface bend bending or other experimental uncertainties.

The influence of the substrate is important in these considerations. Bayer et al. report on $\mathrm{Al}_{2} \mathrm{O}_{3}$ films prepared by T-ALD on ITO and found A12p IS energies between $74.5 \mathrm{eV}$ and $75.5 \mathrm{eV}$ [30]. On ruthenium and ruthenium oxide we found also values between $74.5 \mathrm{eV}$ and $75.0 \mathrm{eV}$ depending on substrate and film thickness [7]. For these conductive oxide substrates the variation in the core level energies may be attributed to surface diploes caused by adsorbed $\mathrm{OH}$ groups. This interpretation is based on the fact that there is a change in the energies of about $0.5 \mathrm{eV}$ when spectra are taken after the precursor pulse and after the oxygen pulse.

In contrast, on non-conductive substrates an interface charge is built up. This is proposed based on electrical studies [29,31] which indicated that a fixed charge is generated at the interface of $\mathrm{Al}_{2} \mathrm{O}_{3}$ /interfacial $\mathrm{SiO}_{2}$. This interface charge induces Coulomb scattering to the surface channel of a field effect transistor which reduces the electron mobility. In our experiments the interface charges cause the additional shift of the core level energies. The amount of such charges varies depending on the individual preparation conditions.
We like to mention that based on our accurate determination of the IS energy we are able to follow shifts in the samples very accurately. In all samples, the IS energy values of the Al2p, $\mathrm{O} 1 \mathrm{~s}$, and the $\mathrm{C} 1 \mathrm{~s}$ level appear to be different. In fact, the variation of the A12p IS energy values for the highest charge level amounts $75.3 \mathrm{eV}$ and for the lowest charge level we find a value of $76.3 \mathrm{eV}$. In total, the shifts of about 1 to $1.5 \mathrm{eV}$ are explained by different charge accumulated. In the PE-ALD samples series (Figure 4, Figure 5 and Figure 6) we find an additional trend as upon increasing temperature there is an additional shift of the $\mathrm{O} 1 \mathrm{~s}$ and $\mathrm{Al} 2 \mathrm{p}$ levels with respect to that of the $\mathrm{C} 1 \mathrm{~s}$ level. This shift is attributed to a structural change in the $\mathrm{Al}_{2} \mathrm{O}_{3}$.

To summarize our XPS data analysis, we have identified fragments of the precursor and the $\mathrm{H}_{2} \mathrm{O}$ oxidant within the films. $\mathrm{OH}$ and $\mathrm{COO}$ groups appear in the O1s core level, TMA fragments and carbon-oxygen reaction products up to COO show up in the $\mathrm{C} 1 \mathrm{~s}$ core level. The relative intensity of both is higher in the PE-ALD films because of the higher reactivity of the plasma enhanced mode. The peak positions of all films are influenced by charged species within the films.

\section{Carbon contamination (EDX, XPS, ellipsometry)}

In order to discuss the integration of carbon atoms into the films we conducted energy dispersive X-ray spectroscopy (EDX), XPS C1s core level spectroscopy, and spectroscopic ellipsometry.

The chemical composition of the $\mathrm{Al}_{2} \mathrm{O}_{3}$ films at different temperatures was investigated by EDX. Hereby, the relation between $\mathrm{C}$-atoms and $\mathrm{Al}$-atoms within the films was determined. Figure 10a displays the ratio of carbon to aluminum depending on the substrate temperature of the film. With

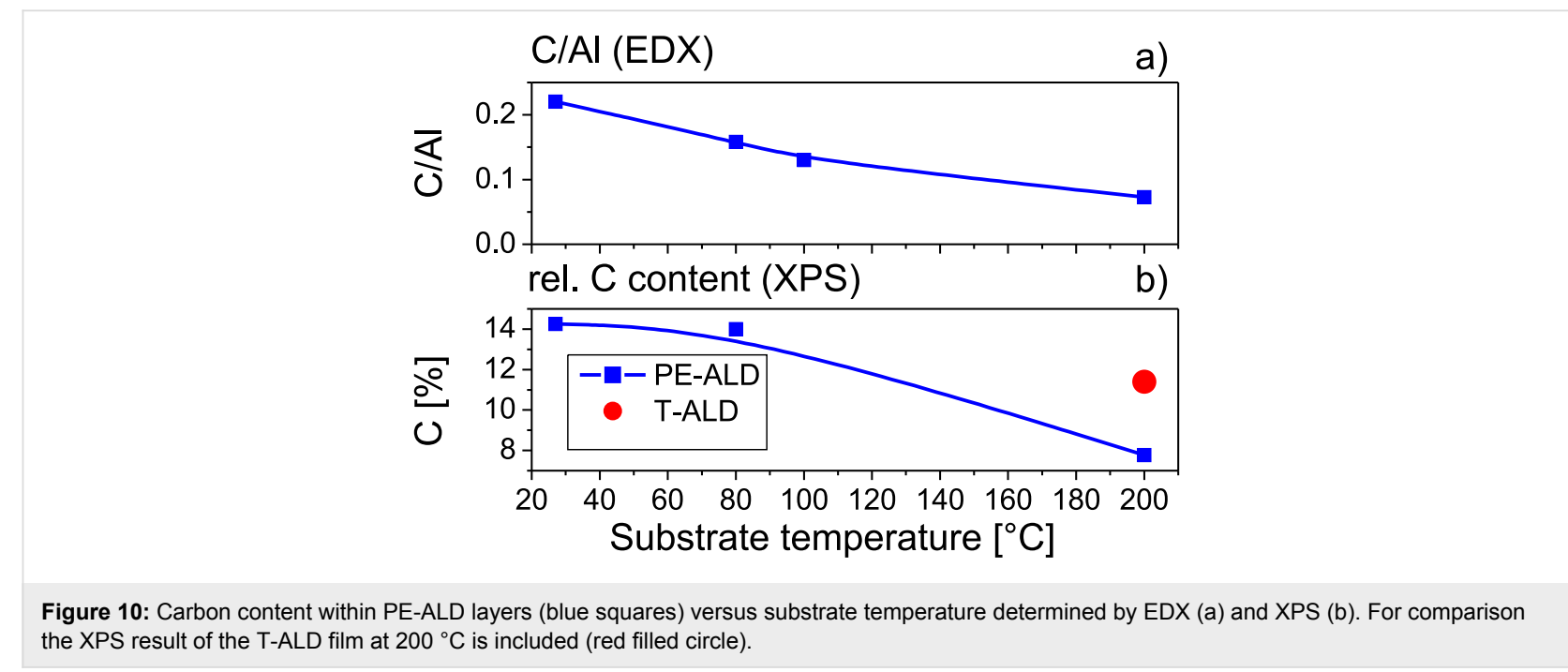


decreasing deposition temperature, the carbon proportion within the $\mathrm{Al}_{2} \mathrm{O}_{3}$ films increases significantly.

The same trend is observed in the XPS data (refer to Figure 5). Here the C1s peak areas with a cross section of 0.021314 [28] were related to the total sum of the cross section weighted $\mathrm{O} 1 \mathrm{~s}$, A12p and C1s peak areas of every sample. The resulting total carbon concentrations are shown in Figure 10b; the corresponding $\mathrm{C} 1 \mathrm{~s}$ core level data are presented in Figure 5. Remarkably, the PE-ALD at $200{ }^{\circ} \mathrm{C}$ exhibits a clear reduction to around $8 \%$ compared to $11 \%$ of the T-ALD at this temperature. The lower carbon content of the PE-ALD sample at $200{ }^{\circ} \mathrm{C}$ is also evident by a qualitative comparison of the normalized $\mathrm{C} 1 \mathrm{~s}$ core levels as depicted in Figure 5. At lower temperatures of $80{ }^{\circ} \mathrm{C}$ and $\mathrm{rt}$ the carbon concentration increases to about $14 \%$. As the carbon concentration shows the same trend as the $\mathrm{O} / \mathrm{Al}$ ratios reported above we argue that the metal precursor interaction with the substrate is not completed leading to higher carbon and lower oxygen contents.

This fact is further supported by carbonate contributions rising in the $\mathrm{C} 1 \mathrm{~s}$ core level data of the PE-ALD samples prepared at $80{ }^{\circ} \mathrm{C}$ and $\mathrm{rt}$ (see Figure 5). In the PE-ALD combustion-like reactions occur with the formation of $\mathrm{COO}$ and $\mathrm{H}_{2} \mathrm{O}$ [1] which may also support secondary reaction pathways [18] leading for example to carbonates and carbon contamination.

It has to be pointed out that the XPS measurements were performed ex-situ and the results might be strongly influenced by surface contamination due to the ex-situ handling of the samples in particular in the surface sensitive XPS method. Nevertheless, our elemental composition data confirm findings of other authors based on RBS data [1,20]. In addition, the observed trend of carbon components within the films is similar to the EDX measurements shown above and the infrared data reported now.

The incorporation of CH-molecule groups was also monitored by means of infrared spectroscopy. For this purpose, spectroscopic ellipsometry is particularly suitable because hereby the influence of substrate properties can be neglected and no distracting overlays with substrate bands occur and the measured spectra can be directly fitted using an appropriate model. The optical properties of the deposited films were modeled using a Brendel oscillator model. The parameters of the oscillator model are: oscillator frequency, oscillator strength, oscillator damping, and a distribution factor taking into account the influence of surrounding materials of the single oscillator. This model can be applied for all absorbing molecule groups in the $\mathrm{Al}_{2} \mathrm{O}_{3}$ film. In the infrared the thin native oxide film cannot be measured and was neglected. Figure 11 shows the measured spectral dependency between the extinction coefficients (absorption indices) of PE-ALD films with different deposition temperatures. In the graph the positions of oscillation bands caused by $\mathrm{Al}-\mathrm{O}$, methyl $\left(\mathrm{CH}_{3}\right)$, and $\mathrm{CH}$ groups are indicated. For lower growth temperatures $\left(80^{\circ} \mathrm{C}, \mathrm{rt}\right)$ the spectra exhibit distinct contributions of methyl and $\mathrm{CH}$ groups indicating not terminated surface reactions of the TMA precursor. At $200{ }^{\circ} \mathrm{C}$ no more carbon-based bands are detectable. In reverse, with decreasing concentration of carbon groups, the absorption by the $\mathrm{Al}-\mathrm{O}$ oscillation band increases indicative for efficient $\mathrm{ALD} \mathrm{Al}_{2} \mathrm{O}_{3}$ reaction [15]. These data are in good agreement to the O/Al ratios and the EDX and XPS carbon measurements. However in the $200{ }^{\circ} \mathrm{C}$ PE-ALD sample no more $\mathrm{CH}_{\mathrm{x}}$ bands are detected, whereas the XPS still reflects carbon and carbonate contributions within the films. XPS is a more surface sensitive method than the infrared spectroscopy. Therefore, we conclude that $\mathrm{CH}_{\mathrm{X}}$ bonds are integrated within the volume of the PE-ALD layers at lower temperatures, whereas carbon contamination and carbonate formation is occurring at the surface.

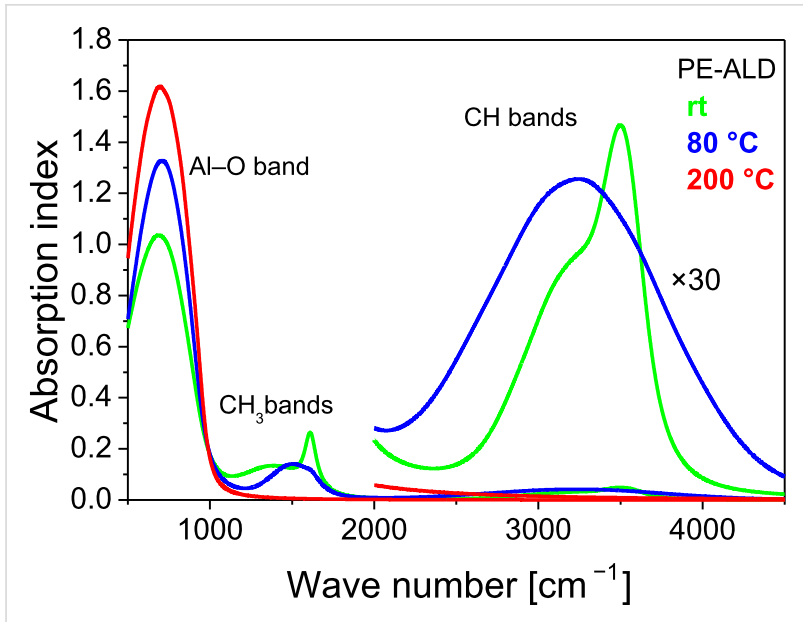

Figure 11: Infrared absorption index data for PE-ALD layers deposited at $200{ }^{\circ} \mathrm{C}$ (red curve), $80^{\circ} \mathrm{C}$ (blue) and $\mathrm{rt}$ (green). The region of the $\mathrm{CH}$ bands is magnified $(\times 30)$.

\section{Conclusion}

Thin homogenous $\mathrm{Al}_{2} \mathrm{O}_{3}$ layers were successfully produced by standard thermal $\left(200{ }^{\circ} \mathrm{C}\right)$ and plasma enhanced ALD in the SENTECH SI ALD LL system at substrates temperatures ranging from $200{ }^{\circ} \mathrm{C}$ down to $\mathrm{rt}$. Comparing the $200{ }^{\circ} \mathrm{C}$ processes similar refractive indices of 1.64 and oxygen to aluminum elemental ratios near the stoichiometric value of 1.5 were observed. However, the PE-ALD at this temperature exhibits favorably increased growth rates and reduced carbon contaminations. The reduction of the deposition temperature of the PE-ALD down to rt leads to the integration of carbon, COO and $\mathrm{CH}_{\mathrm{x}}$ compounds. Methyl groups and derivatives of the 
TMA precursor are integrated into the film due to not completed surface reactions of the aluminum and oxygen precursors. As a result the refractive index and oxygen to aluminum elemental ratio are decreased whereas the growth rate is increased. Nevertheless, the homogeneity of the film growth is not significantly influenced. We conclude that the PE-ALD process at lower temperatures needs therefore an optimization of the cycle and purge time combinations.

Our results contribute to possible deposition on thermally fragile substrates $[8,15]$ and to higher throughput processes in industrial applications [18].

\section{Experimental}

SENTECH's SI ALD LL system shown schematically in Figure 12 is equipped with a plasma source for PE-ALD processes. The capacitive coupled plasma source (CCP source) was developed by SENTECH Instruments and guarantees a stable pulse operation in ALD cycles. Furthermore, no automatic matching of CCP source during PE-ALD process is needed: the plasma source is pulsed with constant matching parameters during the deposition process. Substrate shuck, reactor and precursor lines are equipped with different heaters. The substrate temperature can be controlled in the range between room temperature and $500{ }^{\circ} \mathrm{C}$, reactor and precursor lines can be heated up to $150{ }^{\circ} \mathrm{C}$ and $200{ }^{\circ} \mathrm{C}$ respectively. The system consists of 3 precursor lines.

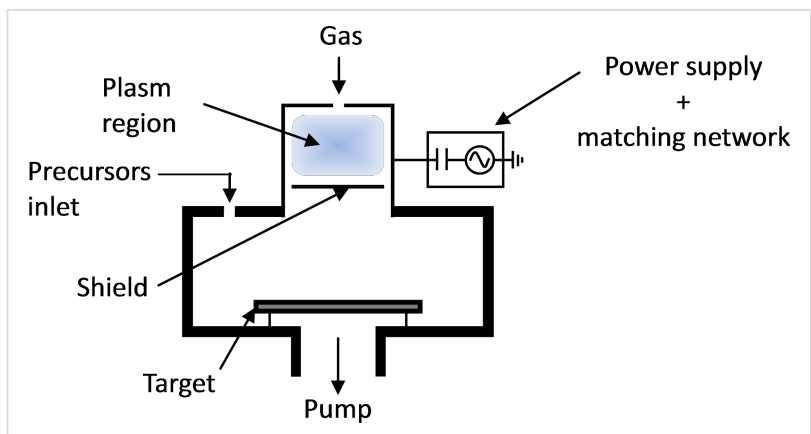

Figure 12: Reactor and CCP source of the SENTECH ALD system: SI ALD LL.

The true remote CCP source, driven by a $13.56 \mathrm{MHz}$ generator, is attached to the upper flange of the reactor. During the deposition process the substrate is placed outside of the plasma generation region; the coated surface is not bombarded with destructive ions and does not see the light from plasma generation region.

PE-ALD $\mathrm{Al}_{2} \mathrm{O}_{3}$ films were deposited on 4" n-type silicon wafers (consisting of a native oxide of approximately $1.5 \mathrm{~nm}$ ) by the SI ALD LL system at $200{ }^{\circ} \mathrm{C}, 150{ }^{\circ} \mathrm{C}, 100{ }^{\circ} \mathrm{C}, 80{ }^{\circ} \mathrm{C}$, and $27{ }^{\circ} \mathrm{C}(\mathrm{rt})$ substrate temperature. Nitrogen $\left(\mathrm{N}_{2}\right)$ with $40 \mathrm{sccm}$ flow was used as carrier gas for TMA. Atomic oxygen was generated by SENTECH's CCP source. Thereby, a constant oxygen flow rate of $75 \mathrm{sccm}$ was adjusted. The pulse duration of the TMA was $120 \mathrm{~ms}$ whereas for the oxygen semi-cycle $5 \mathrm{~s}$ $\left(200{ }^{\circ} \mathrm{C}\right), 6 \mathrm{~s}\left(80^{\circ} \mathrm{C}\right)$ or $7 \mathrm{~s}(\mathrm{rt})$ were chosen. The plasma source was run in a pulsed mode as it was operated only during the oxygen step of the ALD cycle with a power of $100 \mathrm{~W}$ except for the rt sample $(50 \mathrm{~W})$. Process pressure was $20 \mathrm{~Pa}$.

For the T-ALD also $\mathrm{N}_{2}$ with $120 \mathrm{sccm}$ flow rate was used as carrier gas for TMA and $\mathrm{H}_{2} \mathrm{O}$ which was applied as oxygen source. Here, the pulse duration was $60 \mathrm{~ms}$ for both the TMA and $\mathrm{H}_{2} \mathrm{O}$. Process pressure was $12 \mathrm{~Pa}$.

Layers of about $50 \mathrm{~nm}$ were produced for the ellipsometry investigation of the film properties. To determine film thickness and refractive index spectroscopic ellipsometry (SE 800, SENTECH Instruments $\mathrm{GmbH}$ ) was used within the UV-vis spectral range. The SENTECH SE 800 is equipped with a scan analyzer for highly accurate spectra. The measurements were performed at an angle of incidence of $70^{\circ}$ using a spectral range of 280-850 nm (1.5-4.4 eV). The accumulated spectra were modeled using SpectraRay 3 software. The model layers comprised a $\mathrm{Si}$ substrate, a fixed layer of $1.5 \mathrm{~nm}$ native $\mathrm{SiO}_{2}$ and the deposited $\mathrm{Al}_{2} \mathrm{O}_{3}$ film. The $\mathrm{SiO}_{2}$ and the $\mathrm{Al}_{2} \mathrm{O}_{3}$ layers were defined as Cauchy layers. For the detection of $\mathrm{CH}_{\mathrm{x}}$ compounds within the deposited films spectroscopic ellipsometry in the middle infrared wavelength range (MIR) the SENDIRA ellipsometer from SENTECH Instruments GmbH was performed. A Step scan analyser for high spectroscopic accuracy was used at an angle of incidence of $70^{\circ}$. Modelling was carried out using SpectraRay 3 software. The model layer comprised $\mathrm{Al}_{2} \mathrm{O}_{3}$ on $\mathrm{Si}$-substrate and the layer was modelled over the wave number range of $600 \mathrm{~cm}^{-1}$ to $4500 \mathrm{~cm}^{-1}$. Additionally, EDX was applied on these samples $(\approx 50 \mathrm{~nm})$.

For XPS measurements $\mathrm{Al}_{2} \mathrm{O}_{3}$ films with a thickness of about $10 \mathrm{~nm}$ were prepared in order to avoid charging of the samples. XPS measurements were performed either by Specs Mg K $\alpha$ source (in the lab) or by synchrotron radiation (undulator beamline U49/2-PGM2 at BESSY-II in Berlin/Adlershof). The data were recorded using semispherical electron analyzers made by Leybold-Heraeus (lab) or Omicron NanoTechnology GmbH (EA125 at BESSY). Both, beam line monochromator and analyzers are controlled for their accuracy in determining the IS energy by running Au4f (87 eV IS energy) spectra at different excitation energies. All spectra shown in this contribution were Shirley background corrected [32]. The kind of normalization of the XPS spectra is given separately in every related figure caption. 


\section{Acknowledgements}

The authors like to thank experimental support of. G. Beuckert and the BESSY staff. This work is supported by German Federal Ministry of Education and Research (BMBF, 03IN2V4A, 03IN2V4B).

\section{References}

1. Dingemans, G.; Kessels, W. M. M. J. Vac. Sci. Technol., A 2012, 30, 040802. doi:10.1116/1.4728205

2. Sarkar, S.; Culp, J. H.; Whyland, J. T.; Garvan, M.; Misra, V. Org. Electron. 2010, 11, 1896-1900. doi:10.1016/j.orgel.2010.08.020

3. Henkel, K.; Torche, M.; Sohal, R.; Karavaev, K.; Burkov, Y.; Schwiertz, C.; Schmeißer, D. Phys. Status Solidi A 2011, 208, 317-329. doi:10.1002/pssa.201026404

4. Cho, M.; Park, H. B.; Park, J.; Hwang, C. S.; Lee, J.-C.; Oh, S.-J.; Jeong, J.; Hyun, K. S.; Kang, H.-S.; Kim, Y.-W.; Lee, J.-H. J. Appl. Phys. 2003, 94, 2563-2571. doi:10.1063/1.1590414

5. Henkel, K.; Seime, B.; Paloumpa, I.; Müller, K.; Schmeißer, D. IOP Conf. Ser.: Mater. Sci. Eng. 2010, 8, 012036. doi:10.1088/1757-899X/8/1/012036

6. Tallarida, M.; Weisheit, M.; Kolanek, K.; Michling, M.; Engelmann, H.-J.; Schmeißer, D. J. Nanopart. Res. 2011, 13, 5975-5983. doi:10.1007/s11051-011-0319-x

7. Tallarida, M.; Kukli, K.; Michling, M.; Ritala, M.; Leskelä, M.; Schmeißer, D. Chem. Mater. 2011, 23, 3159-3168. doi:10.1021/cm200276z

8. Groner, M. D.; Fabreguette, F. H.; Elam, J. W.; George, S. M. Chem. Mater. 2004, 16, 639-645. doi:10.1021/cm0304546

9. Potts, S. E.; Schmalz, L.; Fenker, M.; Díaz, B.; Światowska, J.; Maurice, V.; Seyeux, A.; Marcus, P.; Radnóczi, G.; Tóth, L.; Kessels, W. M. M. J. Electrochem. Soc. 2011, 158, C132-C138. doi:10.1149/1.3560197

10. Peng, Q.; Lewis, J. S.; Hoertz, P. G.; Glass, J. T.; Parsons, G. N. J. Vac. Sci. Technol., A 2012, 30, 010803. doi:10.1116/1.3672027

11. Prasittichai, C.; Hupp, J. T. J. Phys. Chem. Lett. 2010, 1, 1611-1615. doi:10.1021/jz100361f

12. Tien, T.-C.; Pan, F.-M.; Wang, L.-P.; Tsai, F.-Y.; Lin, C. J. Phys. Chem. C 2010, 114, 10048-10053. doi:10.1021/jp1023229

13. Le Formal, F.; Tétreault, N.; Cornuz, M.; Moehl, T.; Grätzel, M.; Sivula, K. Chem. Sci. 2011, 2, 737-743. doi:10.1039/c0sc00578a

14. Jung, Y. S.; Cavanagh, A. S.; Dillon, A. C.; Groner, M. D.; George, S. M.; Lee, S.-H. J. Electrochem. Soc. 2010, 157, A75-A81. doi:10.1149/1.3258274

15. George, S. M. Chem. Rev. 2010, 110, 111-131. doi:10.1021/cr900056b

16. Speck, F.; Ostler, M.; Röhrl, J.; Emtsev, K. V.; Hundhausen, M.; Ley, L.; Seyller, T. Phys. Status Solidi C 2010, 7, 398-401. doi:10.1002/pssc.200982496

17. Heil, S. B. S.; Kudlacek, P.; Langereis, E.; Engeln, R.; van de Sanden, M. C. M.; Kessels, W. M. M. Appl. Phys. Lett. 2006, 89, 131505. doi:10.1063/1.2357886

18. Profijt, H. B.; Potts, S. E.; van de Sanden, M. C. M.; Kessels, W. M. M. J. Vac. Sci. Technol., A 2011, 29, 050801. doi:10.1116/1.3609974

19. Knoops, H. C. M.; Langereis, E.; van de Sanden, M. C. M.; Kessels, W. M. M. J. Electrochem. Soc. 2010, 157, G241-G249. doi:10.1149/1.3491381
20. van Hemmen, J. L.; Heil, S. B. S.; Klootwijk, J. H.; Roozeboom, F.; Hodson, C. J.; van de Sanden, M. C. M.; Kessels, W. M. M. J. Electrochem. Soc. 2007, 154, G165-G169. doi:10.1149/1.2737629

21. Jinesh, K. B.; van Hemmen, J. L.; van de Sanden, M. C. M.; Roozeboom, F.; Klootwijk, J. H.; Besling, W. F. A.; Kessels, W. M. M. J. Electrochem. Soc. 2011, 158, G21-G26. doi:10.1149/1.3517430

22. Rafi, J. M.; Zabala, M.; Beldarrain, O.; Campabadal, F. J. Electrochem. Soc. 2011, 158, G108-G114. doi:10.1149/1.3559458

23. Henkel, K.; Gargouri, H.; Gruska, B.; Arens, M.; Tallarida, M.; Schmeißer, D. J. Vac. Sci. Technol., A 2014, in press.

24. Gougousi, T.; Barua, D.; Young, E. D.; Parsons, G. N. Chem. Mater. 2005, 17, 5093-5100. doi:10.1021/cm0510965

25. Paparazzo, E. Appl. Surf. Sci. 1986, 25, 1-12. doi:10.1016/0169-4332(86)90021-8

26. Himpsel, F. J.; Morar, J. F.; McFeely, F. R.; Pollak, R. A.; Hollinger, G. Phys. Rev. B 1984, 30, 7236-7241. doi:10.1103/PhysRevB.30.7236

27. Sohal, R.; Torche, M.; Henkel, K.; Hoffmann, P.; Tallarida, M.; Schmeißer, D. Mater. Sci. Semicond. Process. 2006, 9, 945-948. doi:10.1016/j.mssp.2006.10.047

28. Yeh, J. J.; Lindau, I. At. Data Nucl. Data Tables 1985, 32, 1-155. doi:10.1016/0092-640X(85)90016-6

29. Johnson, R. S.; Lucovsky, G.; Baumvol, I. J. Vac. Sci. Technol., A 2001, 19, 1353-1360. doi:10.1116/1.1379316

30. Bayer, T. J. M.; Wachau, A.; Fuchs, A.; Deuermeier, J.; Klein, A. Chem. Mater. 2012, 24, 4503-4510. doi:10.1021/cm301732t

31. Hiratani, M.; Torii, K.; Shimamoto, Y.; Saito, S.-I. Appl. Surf. Sci. 2003, 216, 208-214. doi:10.1016/S0169-4332(03)00432-X

32. Repoux, M. Surf. Interface Anal. 1992, 18, 567-570. doi:10.1002/sia.740180719

\section{License and Terms}

This is an Open Access article under the terms of the Creative Commons Attribution License (http://creativecommons.org/licenses/by/2.0), which permits unrestricted use, distribution, and reproduction in any medium, provided the original work is properly cited.

The license is subject to the Beilstein Journal of Nanotechnology terms and conditions: (http://www.beilstein-journals.org/bjnano)

The definitive version of this article is the electronic one which can be found at: doi:10.3762/bjnano.4.83 